\title{
Discriminating Bangladeshi Adults by the Prevalence of Obesity Disability
}

\section{K.C. Bhuyan}

Professor (Retired) of Statistics, Jahangirnagar University, Dhaka, Bangladesh.

Corresponding Author: K.C. Bhuyan, Professor (Retired) of Statistics, Jahangirnagar University, Dhaka, Bangladesh. Email: kcbhuyan2002@yahoo.com

Received date: October 05, 2020; Accepted date: October 09, 2020; Published date: October 30,2020

Citation: K.C. Bhuyan (2020) Discriminating Bangladeshi Adults by the Prevalence of Obesity Disability J. Diabetes and Islet Biology 3(1); DOI: 10.31579/2641-8975/0022

Copyright: ( 2020 , K.C. Bhuyan, This is an open access article distributed under the Creative Commons Attribution License, which permits unrestricted use, distribution, and reproduction in any medium, provided the original work is properly cited.

\begin{abstract}
The results presented here was derived in analyzing the data collected in investigating 900 adults from both urban and rural areas of Bangladesh to identify some of the socioeconomic variables responsible in discriminating obese disable adults from adults without this health problem. The sample contained $29.5 \%$ obese adults and $8.3 \%$ of them were disable. Level of obesity was significantly associated with different types of health hazard including disability. Obesity disability was predominant among females, illiterate persons, and physically inactive persons, high income group of persons and in diabetic adults. The most responsible variable for prevalence of obesity disability was level of body mass index followed by prevalence of diabetes, hypertension and illiteracy, and non-involvement in physical labor. These variables were identified by discriminant analysis.
\end{abstract}

Keywords: obesity; disability; socioeconomic variables; discriminant analysis; correlation coefficient of discriminant function score and socioeconomic variable

\section{Introduction}

Obesity and overweight are the responsible factors for many chronic noncommunicable diseases, viz diabetes, hypertension, cardiovascular diseases, neuropathic pain and inflammation, migraine, musculoskelated system disorders such as low back pain, osteoarthrities, neck pain, attention deficit hyperactivity disorder, blindness and version problems, deaf-blind, epilepsy or seizures, head injury, deformity of foot or leg, arm, finger, learning disorder, mental retardation, emotional problem, missing legs, feet, hands, paralysis of any kind, spinal chord injury, and many others poor health conditions $[1,2,3,4,5,6,7,8,9]$. The prevalence of obesity was increasing in many countries due to upward social mobility and the problem was shifting towards lower socioeconomic group of people $[10,11,12$, and 13$]$. The problem of obesity was also in increasing trend in developed countries [10,11, 12, 13, 14, and 15]. It is a growing problem worldwide and is associated with a range of comorbidities, including cognitive dysfunction $[5,16]$. It is negatively correlated with quality life and physical activity [17].

In 2016, WHO reported that the overweight adults were 1.9 billion and obese adults were 650 million throughout the world $[18,19]$. Thus, World Health Organization considers this health problem as the major cause of non-communicable diseases and these diseases are the major health burden in the industrialized countries owing to demographic transitions and changing lifestyles among the people. Behavioral factors have significant effects on metabolic risk. The developed and developing countries are facing high risk of obesity and its adverse consequences due to unhygienic food habit, sedentary activities and lifestyles [19-23]. Beside these, some other socioeconomic variable are also responsible for obesity and its adverse consequences [24-25].
In this paper, an attempt was made to identify some socioeconomic variables responsible for obesity and disability simultaneously among some adults in Bangladesh by discriminating obese- disable adults from other.

\section{Methodology}

According to the objective of the study an attempt was made to collect data from both diabetic and non- diabetic adults of ages 18 years and above living in both urban and rural localities of Bangladesh. A big group of diabetic adults were targeted to ensure large number of obese people as obesity and prevalence of diabetes were associated [1, 2, 24, and 26]. The investigated diabetic patients were 544. To study the variability of socioeconomic variables for diabetic and non-diabetic subjects, some respondents were also investigated as a control group. The number of this latter group of respondents was 346 and they were the parents/guardians of the 200 randomly selected students of the American International University - Bangladesh. However, among this latter group of respondents also 91 were found diabetic patients. Thus, finally, out of 900 adults there were 635 diabetic patients and 265 normal subjects.

The data were collected through a pre-designed and pre-tested questionnaire during the months of May and June, 2015 by some undergraduate and post graduate students of American International University-Bangladesh, most of whom were doctors and nurses, of the department of Public Health and they were associated with public health services. The data were collected from the diabetic patients of the working places of the investigators according to their convenience.

The collected data were related to socio-demographic characteristics of each person, viz. age, height weight, marital status, residence, education, 
occupation, income, religion, food habit, smoking habit, involvement in physical activities, physical exercise, prevalence of diabetes, treatment and prevalence of complications due to diabetes, type of diabetes, precautions against the disease, , latest measurement of blood sugar level by authentic body. Some of the variables recorded were qualitative in character and some were quantitative. All variables were transformed to nominal form by assigning numbers to ease the required analysis.

The association of simultaneous prevalence of obesity and disability of respondents with different socioeconomic variables were investigated by Chi-square test. The significance of association was decided when the pvalue of the Chi-square test statistic was less than or equal to 0.05. Irrespective of significance or insignificance association the risk ratio (R.R) of a level of social characteristic in favor of prevalence of obesity disability was calculated along with confidence interval [C.I] of R.R. Discriminant analysis was done to discriminate the obese-disable adults from other groups of respondents. The discrimination helps to identify the responsible factors for the prevalence of obesity- disability [27, 28, and 29]. The analysis was done by using SPSS version 25.0.

The level of obesity was measured by BMI [weight in $\mathrm{kg} /$ height in $(\mathrm{m})^{2}$ ].According to the objective of the study, the respondents were classified as obese (if BMI $\geq 27.5$ ), overweight (if $23 \leq \mathrm{BMI}<27.5$ ), normal (if $18.5 \leq \mathrm{BMI}<23$ ) and underweight (if BMI $<18.5[30,31]$. The adults were classified into 4 groups according to their blood pressure (B.P) level. These groups were optimal (if B.P< 120/80), normal (B.P. < 130/85), high normal (if B.P. $<140 / 90$ ) and hypertensive (if B.P. $\geq 140 /$ 90) [32].

\section{Results}

It was observed from the analysis that out of 900 respondents $29.5 \%$ were obese and $8.3 \%$ of them were disable also [Table 1]. Rate of disability was in significantly increasing trend with the increase in level of BMI $\left[\chi^{2}=43.082\right.$, p-value $\left.=0.000\right]$

\begin{tabular}{|l|l|l|l|l|l|l|l|l|l|l|}
\hline \multirow{2}{*}{$\begin{array}{l}\text { Physical } \\
\text { problem }\end{array}$} & \multicolumn{9}{|c|}{ Level of obesity } & \multicolumn{3}{c|}{ Total } \\
\cline { 2 - 12 } & \multicolumn{2}{|c|}{ Underweight } & \multicolumn{2}{|c|}{ Normal } & \multicolumn{2}{c|}{ Overweight } & \multicolumn{2}{c|}{ Obese } & Number & $\%$ \\
\cline { 2 - 12 } & Number & $\%$ & Number & $\%$ & Number & $\%$ & Number & $\%$ & & \\
\hline None & 23 & 85.2 & 168 & 78.5 & 314 & 79.9 & 209 & 78.6 & 714 & 79.3 \\
\hline Heart & 2 & 7.4 & 13 & 6.1 & 30 & 7.6 & 28 & 10.5 & 73 & 8.1 \\
\hline Eye & 1 & 3.7 & 16 & 7.5 & 13 & 3.3 & 7 & 2.6 & 37 & 4.1 \\
\hline Kidney & 1 & 3.7 & 13 & 6.1 & 24 & 6.1 & 0 & 0.0 & 38 & 4.2 \\
\hline Disability & 0 & 0.0 & 4 & 1.9 & 12 & 3.1 & 22 & 8.3 & 38 & 4.2 \\
\hline Total & 27 & 3.0 & 214 & 23.8 & 393 & 43.7 & 266 & 29.5 & 900 & 100.0 \\
\hline
\end{tabular}

Table 1: Distribution of adults according to level of obesity and prevalence of physical problem.

\begin{tabular}{|l|l|l|l|l|l|l|}
\hline \multirow{2}{*}{ Socioeconomic Factors } & \multicolumn{3}{|c|}{ Prevalence of obesity-disability } & \multicolumn{2}{c|}{ Total } \\
\cline { 2 - 7 } & Yes & No & Number & $\%$ & Number & $\%$ \\
\cline { 2 - 7 } & Number & $\%$ & & & & \\
\hline Residence & & & & & & \\
\hline Rural & 5 & 3.0 & 162 & 97.0 & 167 & 18.6 \\
\hline Urban & 17 & 2.3 & 716 & 97.7 & 733 & 81.4 \\
\hline Total & 22 & 2.4 & 878 & 50.7 & 900 & 100.0 \\
\hline Gender & & & & & & \\
\hline Male & 8 & 1.5 & 522 & 98.5 & 530 & 58.9 \\
\hline Female & 14 & 3.8 & 356 & 96.2 & 370 & 41.1 \\
\hline Marital status & & & & & & \\
\hline Currently married & 22 & 2.6 & 811 & 97.4 & 833 & 92.6 \\
\hline Single & 0 & 0.0 & 67 & 100.0 & 67 & 7.4 \\
\hline Religion & & & & & & \\
\hline Muslim & 21 & 2.7 & 763 & 97.3 & 784 & 87.1 \\
\hline Non-Muslim & 1 & 0.9 & 115 & 99.1 & 116 & 12.9 \\
\hline Age groups (in years $)$ & & & & & & \\
\hline$<25$ & 0 & 0.0 & 19 & 100.0 & 19 & 2.1 \\
\hline $25-40$ & 0 & 0.0 & 124 & 100.0 & 124 & 13.8 \\
\hline $40-50$ & 9 & 3.2 & 272 & 96.8 & 281 & 31.2 \\
\hline $50^{+}$ & 13 & 2.7 & 463 & 97.3 & 476 & 52.9 \\
\hline Level of education & & & & & & \\
\hline Illiterate & 3 & 8.3 & 33 & 91.7 & 36 & 4.0 \\
\hline Primary & 3 & 3.6 & 80 & 96.4 & 83 & 9.2 \\
\hline Secondary & 5 & 2.3 & 213 & 97.7 & 218 & 24.2 \\
\hline Graduate & 10 & 2.8 & 352 & 97.2 & 362 & 40.2 \\
\hline Higher & 1 & 0.5 & 200 & 99.5 & 201 & 22.4 \\
\hline Occupation & 1 & 0.5 & 206 & 99.5 & 207 & 23.0 \\
\hline Business & 5 & 2.0 & 243 & 98.0 & 248 & 27.6 \\
\hline Service & 10 & 5.6 & 170 & 94.4 & 180 & 20.0 \\
\hline Housewife & & & & & & \\
\hline & & & & & \\
\hline
\end{tabular}




\begin{tabular}{|l|l|l|l|l|l|l|}
\hline Farming & 1 & 0.6 & 153 & 99.4 & 154 & 17.1 \\
\hline Others & 5 & 4.5 & 106 & 95.5 & 111 & 12.3 \\
\hline Type of work & & & & & & \\
\hline No physical labor & 7 & 1.5 & 449 & 98.5 & 456 & 50.7 \\
\hline Physical labor & 15 & 3.4 & 429 & 96.6 & 444 & 49.3 \\
\hline Smoking habit & & & & & & \\
\hline Yes & 3 & 1.1 & 279 & 98.9 & 282 & 31.3 \\
\hline No & 19 & 3.1 & 599 & 96.9 & 618 & 68.7 \\
\hline Prevalence of Diabetes & & & & & & \\
\hline Yes & 22 & 3.5 & 613 & 96.5 & 635 & 70.6 \\
\hline No & 0 & 0.0 & 265 & 100.0 & 265 & 29.4 \\
\hline Total & 22 & 2.4 & 878 & 97.6 & 900 & 100.0 \\
\hline
\end{tabular}

Table 2: Distribution of respondents by prevalence of obesity-disability and some socioeconomic factors.

\begin{tabular}{|c|c|c|c|c|c|c|}
\hline \multirow{3}{*}{ Socioeconomic Factors } & \multicolumn{4}{|c|}{ Prevalence of obesity-disability } & \multirow{2}{*}{\multicolumn{2}{|c|}{ Total }} \\
\hline & \multicolumn{2}{|c|}{ Yes } & \multicolumn{2}{|l|}{ No } & & \\
\hline & Number & $\%$ & Number & $\%$ & Number & $\%$ \\
\hline \multicolumn{7}{|l|}{ Income ( in 000 taka) } \\
\hline$<30$ & 9 & 2.8 & 308 & 97.2 & 317 & 35.2 \\
\hline $30-50$ & 1 & 0.8 & 118 & 99.2 & 119 & 13.2 \\
\hline $50-70$ & 2 & 1.3 & 155 & 98.7 & 157 & 17.4 \\
\hline $70-90$ & 0 & 0.0 & 129 & 100.0 & 129 & 14.3 \\
\hline $90^{+}$ & 10 & 5.6 & 168 & 94.4 & 178 & 19.8 \\
\hline \multicolumn{7}{|l|}{ Expenditure ( in 000 taka) } \\
\hline$<20$ & 11 & 2.9 & 362 & 97.1 & 373 & 41.4 \\
\hline $20-40$ & 1 & 0.6 & 178 & 99.6 & 179 & 19.9 \\
\hline $40-60$ & 4 & 2.2 & 179 & 97.8 & 183 & 20.3 \\
\hline $60-80$ & 5 & 3.8 & 125 & 96.2 & 130 & 14.4 \\
\hline $80+$ & 1 & 2.9 & 34 & 97.3 & 35 & 3.9 \\
\hline \multicolumn{7}{|l|}{ Hypertension } \\
\hline Optimal & 8 & 1.6 & 494 & 98.4 & 502 & 55.8 \\
\hline Normal & 8 & 2.7 & 288 & 97.3 & 296 & 32.9 \\
\hline High normal & 4 & 5.3 & 72 & 94.7 & 76 & 8.4 \\
\hline hypertensive & 2 & 7.7 & 24 & 92.3 & 26 & 2.9 \\
\hline Total & 22 & 2.3 & 878 & 97.6 & 900 & 100.0 \\
\hline
\end{tabular}

Table 2: Distribution of respondents by prevalence of obesity-disability and some socioeconomic factors.

The rural adults were only $18.6 \%$ but $3.0 \%$ of them were suffering simultaneously from both obesity and disability. Though prevalence of obesity disability was not significantly associated with residence, still the risk of this health problem for rural adults was 1.20 times as it was for urban adults [ R.R=1.20; C.I $\{0.48,3.44\} ; \chi^{2}=0.260$., p-value- $\left.=0.610\right]$. The percentage of female respondents was 41.1 and $3.8 \%$ of them were affected by this health hazard. The risk of prevalence of obesity disability for females was 2.51 times as it was for males [R.R. $=2.51$, C.I $\{1.06$, $5.92\}]$. The prevalence of this health problem was significantly associated with gender variation [ $\chi^{2}=4.726, \mathrm{p}-$ value $=0.030$ ]. In the sample $87.1 \%$ were Muslims and $2.7 \%$ of them were the patients of obesity- disability. However, religion was not significantly associated with prevalence of obesity-disability [ $\chi^{2}=1.398, \mathrm{p}-$-value $=0.237$ ]. But the risk for Muslim respondents was 3.11 times as it was for non-Muslim adults [R.R. $=3.11$, C.I. $\{0.42,22.92\}]$. The percentage of married persons was 92.6 and prevalence of obesity-disability was prevailed among $2.6 \%$ of them. No currently single adult of the sample was facing the problem of this health hazard. However, marital status was not significantly associated with prevalence of obesity-disability [ $\chi^{2}=1.814, \mathrm{p}-$ value $=0.178$ ]. This study indicated that single adult had no risk of prevalence of this health problem. The sample adults of ages less than 40 years were $15.9 \%$ and none of them had the experience of prevalence of obesity disability. More (3.2\%) obese and disable adults were noted among elderly people of ages 40 to less than 50 years $(31.2 \%)$. The percentage of obese and disable adults was 2.7 among eldest (ages 50 years and above, $52.9 \%$ ) adults. But prevalence of obesity- disability was not significantly changing with the change in age $\left[\chi^{2}=4.425, \mathrm{p}-\right.$ value $\left.=0.219\right]$. But people of ages 40 to 50 years had $17 \%$ more risk compared to the risk of eldest people [R.R. $=1.17$, C.I. $\{0.51,2.70\}]$. The percentage of illiterate respondents in the sample was 4.0 and $8.3 \%$ of them were the patients of obesity-disability. The rate of prevalence was significantly decreasing with the increase in level of education $\left[\chi^{2}=9.081, \mathrm{p}\right.$-value $\left.=0.039\right]$. The chance of prevalence in illiterate adults was 3.79 times as it was in adults of other levels of education [R.R. $=3.79$, C.I $\{1.19,12.09\}]$. Twenty per cent sample respondents were housewives and $5.6 \%$ of them were facing the problem of obesity-disability. The chance of prevalence was 3.33 times among this group compared to the chance of others [R. R. $=3.33$, C.I. $\{1.46,7.58\}]$. The prevalence of obesity-disability rates among servicemen $(27.6 \%)$, businessmen $(23 \%)$ and farmers $(17.1 \%)$ were $2.0 \%$, $0.5 \%$ and $0.6 \%$, respectively. But prevalence of this health problem was significantly associated with profession of the adults $\left[\chi^{2}=14.892, \mathrm{p}\right.$ value $=0.005]$. The percentage of physically inactive adults was 50.7 and $1.5 \%$ of them were the patients of obesity-disability. The prevalence rate 
was higher (3.4\%) among physically active adults (49.3\%). The chance of prevalence for this group was 2.20 times as it was in physically inactive adults [R.R. $=2.20$, C.I. $\{0.91,5.35\}]$. Level of family income was significantly associated with prevalence of obesity-disability and 5.6\% adults belonged to [ $\chi^{2}=13.143, \mathrm{p}-$-value $=0.011$ ] families of highest income group (19.8\%) were suffering from this health hazard. The chance of prevalence was 3.38 times among this group as it was in others [R.R. $=3.38$, C.I. $\{1.48,7.70\}]$. Level of family expenditure was not significantly associated with prevalence of obesity-disability $\left[\chi^{2}\right.$ $=4.215$, p-value $=0.378]$. But prevalence rate was higher in adults belonged to families spending highest amount as family expenditure (Tk. 60 thousand and above). The percentage of adults of these families was 18.3 and $3.6 \%$ of them were suffering. The chance of prevalence for this group was 1.67 times compared to the chance of others [R.R. $=1.67$, C.I $\{0.66,4.20\}]$.

Only $2.9 \%$ adults were hypertensive and $7.7 \%$ of them were suffering from obesity-disability as against $2.4 \%$ adults of this category in the sample. The chance of prevalence of obesity- disability was 3.36 times for hypertensive adults compared to the chance of other respondents [R.R.=3.36,C.I. $\{0.48,23.57\}]$.The rate of prevalence was increased with the increase in level of blood pressure of adults, though this increase was not statistically significant $\left[\chi^{2}=7.141, \mathrm{p}-\right.$ value $=0.068$ ]. All the obesedisable adults in the sample were diabetic patients (70.6\%). None of the non-diabetic adults $(29.4 \%)$ was suffering from obesity-disability at the same time. However, prevalence of diabetes and prevalence of obesitydisability were significantly associated $\left[\chi^{2}=9.411\right.$, $\mathrm{p}$-value $\left.=0.002\right]$. The percentage of non-smoker adults was 68.7 and $3.1 \%$ of them were patient's obesity-disability. The chance of prevalence of this health problem in these adults was 3.63 times as it was in smokers [R.R. $=3.63$, C.I. $\{1.08,12.16\}]$. However, smoking habit and prevalence of obesitydisability was not significantly associated $\left[\chi^{2}=3.283\right.$, p-value $\left.=0.070\right]$.

\section{Discriminant analysis}

According to the objective of the study attempt was made to discriminate adults suffering simultaneously from obesity and disability from other adults. The variables included for discrimination were residence, religion, gender, age, marital status, education, profession, family income and expenditure, body mass index, prevalence of diabetes, blood pressure, and smoking habit. As a step of analysis, the differences in these variables for two groups of adults were investigated by F- test. It was observed that the variables gender, age, education, occupation, body mass index, prevalence of diabetes and blood pressure levels were significantly different for two groups. The discriminant analysis was also significant [ $\Lambda=0.908, \chi^{2}=85.768, \mathrm{p}-$ value $\left.=0.000\right]$ indicating that the two groups of adults were discriminated well. The method identified the most important variable for discrimination depending on the highest absolute value of correlation coefficient(r) of discriminant function score with socioeconomic variable. The results were shown in Table 3 below:

The most important variable or discrimination was body mass index followed by prevalence of diabetes, level of blood pressure, education, occupation, gender, and age.

\begin{tabular}{|l|l|l|l|l|l|}
\hline Variables & $\Lambda$ & F - statistic & p-value & $\begin{array}{l}\text { Discriminant } \\
\text { function coefficient }\end{array}$ & $\begin{array}{l}\text { Correlation } \\
\text { discriminant } \\
\text { variable, } \mathbf{r}\end{array}$ \\
\hline Bodynction mass index & 0.932 & 65.484 & 0.000 & 0.833 & 0.850 \\
\hline Prevalence of diabetes & 0.990 & 9.489 & 0.002 & -0.271 & -0.323 \\
\hline Level of blood pressure & 0.993 & 6.653 & 0.011 & 0.266 & 0.269 \\
\hline Education & 0.993 & 6.068 & 0.014 & -0.251 & -0.259 \\
\hline Occupation & 0.994 & 5.275 & 0.022 & 0.131 & 0.241 \\
\hline Gender & 0.995 & 4.741 & 0.030 & -0.079 & 0.229 \\
\hline Age & 0.995 & 4.872 & 0.028 & -0.132 & 0.152 \\
\hline Smoking habit & 0.996 & 3.287 & 0.070 & 0.115 & 0.190 \\
\hline Income & 0.998 & 2.015 & 0.156 & 0.217 & 0.141 \\
\hline Marital status & 0.998 & 1.813 & 0.178 & -0.037 & -0.141 \\
\hline Religion & 0.998 & 1.397 & 0.237 & -0.132 & -0.124 \\
\hline Residence & 1.000 & 0.259 & 0.611 & -0.018 & -0.053 \\
\hline Expenditure & 1.000 & 0.091 & 0.762 & -0.165 & 0.023 \\
\hline
\end{tabular}

Table 3: Results of discriminant analysis

\section{Discussion}

The prevalence of overweight and obesity are in increasing trend from the last decades [10-12] and these are the sources of at least 30 noncommunicable chronic diseases including different types of disabilities [6 -9, 33-36]. Body mass index has been identified as key health indicator and determination of health for people including intellectual disability [35]. Except social factors, some dietary factors and physical activity and sedentary activity are responsible for obesity [25, 35, and 37]. This study was planned to identify some socioeconomic variables responsible for simultaneous prevalence of obesity and disability.

For the study, 900 adults of ages 18 years and above were investigated from both urban and rural areas of Bangladesh. Among the adults $29.5 \%$ were obese and $8.3 \%$ of them had some physical disability. The sample disable adults were $2.4 \%$. The percentages of prevalence of obesitydisability in rural people, females, Muslims, married adults, elderly people (40 years and above), illiterate people, housewives, adults of higher family income and higher family expenditure were $3.0 \%, 3.8 \%$, $2.7 \%, 2.6 \%, 2.9 \%, 8.3 \%, 5.6 \%, 5.6 \%, 3.6 \%$, respectively. These percentages were higher compared to the overall percentage of obesedisable adults in the sample. These percentages of obese-disable adults were for a particular level of some of the social variables. All these variables mentioned above were not significantly associated with the prevalence of obesity disability of the adults. The significantly associated variables were gender, marital status, education, occupation, and family income. Similar results were noted in some earlier studies also [5, 25, and 38]. But, adults of the above mentioned categories were at higher risk of prevalence of the disease. Level of blood pressure and prevalence of 
diabetes were significantly associated with obesity-disability. All obese disable adults were diabetic and $7.7 \%$ of them were hypertensive. The chance of prevalence of the problem among hypertensive adults was more than three times as it was in others.

The different socioeconomic variables were not similarly responsible for the prevalence of obesity-disability. This was also observed from the study of the risk ratios. However, most important variables was body mass index followed by prevalence of diabetes, level of blood pressure, education, occupation and gender. These variables were identified by discriminant analysis.

\section{Conclusion}

The objective of the study was to identify the risk and responsible factors for the prevalence of obesity disability among the adults of Bangladesh as obesity is a growing health hazard worldwide. It is one of the major risk factor for many non-communicable and chronic diseases. According to the objective of the study, the analysis was done using the data of 900 adults residing in both urban and rural areas of Bangladesh. The investigation of risk and responsible variables was done by calculating risk ratio and discriminant analysis, respectively. The results indicated that level of obesity was significantly associated with different types of physical problems. Again, prevalence of obesity-disability was associated with some of the socioeconomic variables under study. The associated variables were gender, education, occupation, income, prevalence of diabetes, and prevalence of hypertension. From both the analytical results it can be concluded that obesity, prevalence of diabetes, hypertension, and illiteracy were the responsible factors for obesity-disability. The disease was more prevalent among females and housewives.

Due to upward social mobility, obesity and its related diseases cannot be avoided. But there should be some steps to reduce the rate of obesity, especially in adults. Some of the suggested steps are

(i) Control the body weight by doing some physical work and physical exercise. Develop the habit of walking whenever it is possible,

(ii) Prefer homemade food and avoid restaurant and can food, salty and fatty food as per as possible,

(iii) Avoid smoking and taking drugs and drinks.

Government agencies, health service providers in both urban and rural areas, social workers and private medical practitioners can encourage the people to follow the above suggestions.

\section{References}

1. Mokdad, A.H.; Ford,E.S.; Bowman,B.A.; Dietz, W.H.; Vinicor,F.; Bales,V.S. and Marks,J.S. (2003): Prevalence of obesity, diabetes, and obesity-related health risk factors 2001, JAMA, 289,76- 79 .

2. Barnes, S.A. (2011): The epidemic of obesity and diabetes: Trend and treatment, Tex Heart Inst., 38(2), $142-144$.

3. Bigal,M.E.; Lipton, R.B.; Holland, P.R. and Goadsby, P.J. (2007): Obesity, migraine, and chronic migraine : Possible mechanisms of interaction, Neurology, 68(21), 1851- 1861.

4. Miller, A.A.; Spencer, S.J. (2014): Obesity and neuroinflammation: a pathway to cognitive impairment, brain, behavior and immunity, 42, $10-21$.

5. Rimmer, J.H.; Yamaki, K. and Vogel, L.C. (2011): Obesity and overweight prevalence among adolescents and disabilities, Preventing Chronic Disease, 8(2) A41.

6. Tucker, A.; Visscher, T. and Picavet, H. (2009): Overweight and health problems of the lower extremities: 0soarthirites, pain and disability, Public HealthNutrituion, 12(3), 1 - 10.
7. Yun Min Na; Hyun Ah Park; Kang, Young Guy Cho; Kyoung Wokim, Yang ImHur; Yu Na Kim and Su Hyem Lee (2011): Obesity, obesity related diseases and disability, Korean Jour Family Medicine, 37(7), 412 - 422.

8. Peeters, A.; Bonneux,L.; Nusselder, W.J.; D Lact C.and Barendregt , J.J (2004): Adult obesity and the burden of disability throught life, Obes Res, 12, $1145-1151$.

9. Weil, E.; Wachternan, M.; McCarthy, E.P.; Davies, R.B.; O'day B.; Lisa, I.L. and Christina, C.W. (2002): Obesity in adults with disabling conditions, JAMA, 288(10), $1265-1268$.

10. Dhurandhar, N.V. (2004): Contribution of pathogene in human obesity. Drug News \& Perspectives, 7(5), 307- 313.

11. Berg, C.; Rosengren, A.; Aives, N. et al (2005): Trendis in overweight and obesity from 1985 to 2002 in Goteberg, West Sweden, Inter. Jour. Obesity, 29(8), 916- 924.

12. Skliros, E.A.; Merkoures, P.; Sotiropoulos, A. et al (2008): The relationship between body mass index and hypertension in elderly Greeks:The Nemea Primary Care Study, Jour Amer Geriatrics Society, 56(5), $954-955$.

13. Haslam, D.W. and James, W.P. (2005: Obesity, Lancet, 366, $1197-1209$.

14. John, E.H.; Jussara, M do, Carmo.; Alexander, A da Silva.; Zhen, W. and Michael, E.H. (2015): Obesity- Induced hypertension: Interaction of nuerohumoral and renal mechanisms, Circulation Research, 116, $991-1006$.

15. Theodore, A.K. (2010): Obesity-related hypertension: Epidemiology, Pathophysiology, and clinical management, Amer Jour Hypertension, 23(1), 1170 - 1178.

16. Singleton, J.; Volckmann, E.; Graham, T. and Smith, A. (2014): Neurology associated with non-diabetic obesity, 82(10), (s36.006).

17. Lassarre, A.M. ; Glauss,J. ; vandeleur,C.L.; Vidal, M.P.; Voucher, J.; Bastardot, F. Waeber,G. and Vollenweider,P. (2014): Depression with atypical features and increase obesity, body mass index, waist circumference and fat mass: A prospective population -based study, JAMA, Psychiatry, 71(8), 880- 888.

18. Neuman, L. Lerner, E., Glazer, Y., Bolotin, A., Shefer, A and Buskila, D. (2008): A cross-sectional study of the relationship between body mass index and clinical characteristics, tenderness measures, quality life, and physical functioning in fibromualgin patients, Clinical Rheumatology, 27(12), 1543 - 1547.

19. WHO (2020): Fact Sheets/Detail/Obesity and overweight, March 2020.

20. WHO (2007): The Challenge of obesity in the WHO European region and strategies for response; Edited by Branca, F.; Nikogosian,H.; Lobstein, T.C. , Copenhagen.

21. Weiss, R.; Dzria, J.; Burgert, T.S.et al (2004): Obesity and the metabolic syndrome in children and adolescents, N. Engl .J. Med., 350, $2362-2374$.

22. Dinsa, G.D.; Goryakin, Y.; Fumagalli, E. and Suhrcke, M. (2012): Obesity and socioeconomic status in developing countries: A systematic review, Obesity Reviews, 13(11) 106779.

23. Misra, A. and Khurana, L. (2008): Obesity and the metabolic syndrome in developing countries, J Clin. Endocrinal Metab, 93, $51-58$.

24. Mansion, J.E. Willett, W.C., Colditz, G.A.; Hunter, D.J. ; Hankinsom, S.E. et al (1995): Body weight and mortality among women, N Engl J Med, 333, 677- 685.

25. Dinsa, G.D., Goryakin, Y., Fumagalli. E., and Suhrcke, M., (2012): Obesity and socioeconomic status in developing countries: A systematic review, Obesity Reviews, 13(11), 106779. 
26. Bhuyan,K.C. and Fardus,J. (2019): Level of obesity and socioeconomic factors of a group of adult people of Bangladesh: A factor analysis approach, Amer, Jour. Data Mining and Knowledge Discovery, 4(1), 8-14.

27. Bertino, G.; Ardiri, A.M.; Ali, F.T. et al (2006): Obesity and related diseases: an epidemiological study in Western Sicily, Minerva Gastroenterol Dieto, 52(4), 379 - 385.

28. Bhuyan, K.C. (2019): A note on the application of discriminant analysis applied in medical research, Archives of Diabetes and Obesity, 2(2), 142-146.

29. McLachlan, G.J. (2004): Discriminant and Statistical Pattern Recognition, Wiley Inter-science, ISBN 978-0-471-69115-0.

30. Garson, G.D. (2008): Discriminant function analysis.

31. Biswas, T.; Garnett, P. Sarah and Rawal, B.Lal (2017): The prevalence of underweight, overweight, and obesity in Bangladesh: Data from a national survey, PLoS One, 12(5), e0177395.

32. Appropriate Body Mass Index for Asian Population and its Implications for Policy and Intervention Strategies, WHO Expert Consultation, Public Health, Lancet 363, 2004.

33. Jan, A.S.; Yan, Li.; Azusa, H.; KEI, A.; Eamon, D. and O'Brien, E., (2017) Blood pressure measurement anno 2016. Amer Jour Hypertens, 30(5), $453-463$.

34. Katherine, F.G. and Donald, F. (2011): Obesity and disability, Amer Jour Prev Med., 42(5), 541 - 545

35. Raggi, A.; Brunani, A.; Sirtori, A.; Liuzzi, A.;Berselli, M.E.; Valentilla, V.; Francesca, C. and Leonardi, M.(2010): Obesity related disability : key factors identified by the International Classification of Functioning, Disability and Heath, Jour Disability and Rehabilitation, 32.

36. Temple, V.A.; Walkley, J.W.; Greenway, K. (2010): Body mass index as an indicator of adiposity among adults with intellectual disability, Jou Intelle Dev Disability, 35(2), 116 - 120.

37. Ellis,L.J. ; Lang, R. and Shield, J.P. ( 2006): Obesity and disability - a short review, Obes Rev, 7(4), $341-345$.

38. Calamusa, G.; Amodio, E.; Costantino, C.; Maria, D. Pasquate.et al (2012): Body mass index and factors associated with overweight and obesity: a cross-sectional study of adult subjects living in a small city of Western Sicily (Italy), Italian Jour.Pub.Health, 9(3), e7539.

39. Bhuiyan, D. and Bhuyan, K.C. (2019): Discriminating Bangladeshi adults by non-communicable diseases, Rehabilitation Science, 4(3), 35 - 43. 